\title{
Diagnostic practices and disease surveillance in Canadian children with congenital central hypoventilation syndrome
}

\author{
Reshma Amin MD MSc ${ }^{1,2}$, Theo J Moraes MD PhD ${ }^{1,2}$, Amy Skitch BSc ${ }^{1}$, \\ Meredith S Irwin MD ${ }^{1,2}$, Stephen Meyn MD PhD ${ }^{1,2}$, Manisha Witmans MD $^{3}$
}

R Amin, TJ Moraes, A Skitch, MS Irwin, S Meyn, M Witmans. Diagnostic practices and disease surveillance in Canadian children with congenital central hypoventilation syndrome. Can Respir J 2013;20(3):165-170.

OBJECTIVE: To assess the diagnostic and surveillance practices of Canadian pediatric subspecialists for children with congenital central hypoventilation syndrome (CCHS).

METHODS: The present analysis was a prospective cross-sectional study. A web-based survey was sent to 303 pediatric subspecialists in Canada: 85 pediatric respirologists, 77 pediatric neurologists and 141 neonatologists. The survey included 36 questions about the current diagnostic and surveillance management of pediatric CCHS. Differences in responses among respirologists, neurologists and neonatologists were evaluated for each question, where feasible, and responses were compared with the 2010 American Thoracic Society (ATS) Clinical Policy Statement for CCHS. RESULTS: A total of 83 (27\%) participants responded to the survey; the highest survey response rate $(40 \%)$ was from respirologists. For the diagnosis of CCHS, $25 \%$ of respondents did not order genetic testing, either alone or with another test, to make a diagnosis of CCHS. The criteria and tests recommended by the ATS to make a diagnosis of CCHS - genetic testing, diagnosis of exclusion, polysomnogram and plus or minus a hypercapnic challenge - were ordered by $23(43 \%)$ of the 54 respondents. Although polysomnograms were ordered for more than $90 \%$ of children with CCHS, only $37 \%$ of respirologists aimed for a carbon dioxide range of $35 \mathrm{mmHg}$ to $40 \mathrm{mmHg}$ during polysomnogram titrations.

CONCLUSIONS: The results demonstrate variability in the diagnostic and surveillance practices of pediatric subspecialists in children with CCHS across Canada. The present study provides an initial needs assessment and demonstrated that there are significant deviations in practice from the 2010 ATS guidelines.

Key Words: Canada; CCHS; Disease surveillance; PHOX2B

Ongenital central hypoventilation syndrome (CCHS) is a rare genetic disorder characterized by ventilatory insensitivity to hypercapnia and hypoxemia during sleep and/or wakefulness presenting in infancy, childhood or adulthood. Affected individuals have a heterozygous mutation (autosomal dominant) in the paired-like homeobox 2b (PHOX2B) gene, a transcription factor expressed in neurons (1). This disease-defining gene was discovered in $2003(1,2)$. Current reports suggest a total of 1000 patients worldwide; however, this is likely an underestimate (3).

In 1999, the American Thoracic Society (ATS) published a statement on the diagnosis and clinical management of CCHS (4) with an update in 2010 (3). Its purpose was to "aid the clinician in optimizing patient care that will be specifically tailored to knowledge of the individual PHOX2B genotype/mutation" (3). Overall, the guideline informed practitioners that $P H O X 2 B$ mutation is needed for a diagnosis of CCHS. It also introduced the opportunity to anticipate the CCHS phenotype based on genotype; emphasized the importance of parental testing; provided updated information regarding available treatment options; and emphasized the lifelong

\section{Les pratiques de diagnostic et de surveillance des maladies che $z$ les enfants canadiens ayant un syndrome d'Ondine}

OBJECTIF : Évaluer les pratiques de diagnostic et de surveillance des pédiatres surspécialisés canadiens auprès des enfants ayant un syndrome d'Ondine (ou hypoventilation alvéolaire centrale congénitale).

MÉTHODOLOGIE : La présente analyse était une étude transversale prospective. Le chercheurs ont envoyé un sondage virtuel à 288 pédiatres surspécialisés du Canada : 85 pneumologues pédiatres, 77 neurologues pédiatres et 141 néonatologistes. Le sondage contenait 36 questions sur la prise en charge liée au diagnostic et à la surveillance du syndrome d'Ondine pédiatrique. Ils ont analysé les différences entre les pneumologues, les neurologues et les néonatologistes pour chaque question, dans la mesure du possible, et ont comparé les réponses avec le document de politiques cliniques sur le syndrome d'Ondine de 2010 produit par l'American Thoracic Society (ATS). RÉSULTATS : Au total, 83 (27\%) participants ont répondu au sondage. Le taux de réponse le plus élevé ( $40 \%$ ) provenait des pneumologues. Pour diagnostiquer le syndrome d'Ondine, $25 \%$ des répondants ne demandaient pas de test génétique, seul ou conjointement avec un autre test. Vingt-trois (43\%) des 54 répondants ont respecté les critères et les tests recommandés par l'ATS pour diagnostiquer le syndrome d'Ondine (test génétique, diagnostic d'exclusion, polysomnogramme avec ou sans épreuve d'hypercapnie). Même si les surspécialistes ont demandé un polysomnogramme pour plus de $90 \%$ des enfants ayant un syndrome d'Ondine, seulement $37 \%$ des pneumologues visaient une plage de dioxyde de carbone de $35 \mathrm{mmHgà} 40 \mathrm{mmHg}$ pendant le titrage.

CONCLUSIONS : Les résultats démontrent la variabilité des pratiques de diagnostic et de surveillance des pédiatres surspécialisés chez les enfants du Canada présentant un syndrome d'Ondine. La présente étude constitue une évaluation initiale des besoins et démontre d'importantes déviations des pratiques par rapport aux lignes directrices de l'ATS.

need for ventilation and clinical follow-up. Furthermore, the guideline stated that pediatric respirologists should be referring patients to regional pulmonary centres with CCHS expertise for ongoing care. CCHS is a rare condition; therefore, physicians may not be familiar with the diagnosis or optimal management of CCHS, or they may not have access to subspecialists with expertise in CCHS. Missed or delayed diagnoses can have devastating consequences including sudden death.

Presently, Canadian CCHS recommendations do not exist. However, the Canadian Thoracic Society (CTS) recently published home ventilation guidelines based on the adult literature that recommend $\mathrm{PHOX} 2 \mathrm{~B}$ testing in the setting of unexplained central hypoventilation (5). Although the ATS guidelines statement was published in 2010, implementation across Canada is not known. Our hypothesis was that diagnostic disease and surveillance practices by Canadian pediatric subspecialists for children with CCHS in Canada will vary from the 2010 ATS clinical policy statement on CCHS despite the recent CTS guidelines advocating for $\mathrm{PHOX} 2 \mathrm{~B}$ testing in the setting of unexplained hypoventilation.

${ }^{1}$ Department of Paediatrics, The Hospital for Sick Children; ${ }^{2}$ University of Toronto, Toronto, Ontario; ${ }^{3}$ University of Alberta, Edmonton, Alberta Correspondence: Dr Reshma Amin, Hospital for Sick Children, 555 University Avenue, Toronto, Ontario M5G 1 X8.

Telephone 416-813-6346, fax 416-813-6246, e-mail reshma.amin@sickkids.ca 
TABLE 1

Survey response rate according to region

\begin{tabular}{lcc}
\hline & \multicolumn{2}{c}{ Surveys } \\
\cline { 2 - 3 } Region (Canada) & Sent, $\mathbf{n}$ & Completed, $\mathbf{n}(\%)$ \\
\hline East & 183 & $55(30)$ \\
West & 59 & $16(27)$ \\
Maritimes & 25 & $8(32)$ \\
Central & 36 & $4(11)$ \\
\hline
\end{tabular}

TABLE 2

Survey response rate according to subspecialty

\begin{tabular}{lcc}
\hline \multirow{2}{*}{ Subspecialty } & \multicolumn{2}{c}{ Surveys } \\
\cline { 2 - 3 } Pediatric respirology & 85 & Completed, $\mathbf{n}(\%)$ \\
Pediatric neurology & 77 & $34(40)$ \\
Neonatology & 141 & $15(19)$ \\
\hline
\end{tabular}

TABLE 3

Children with congenital central hypoventilation syndrome (CCHS) seen in the past year by pediatric subspecialists

\begin{tabular}{lcccc}
\hline $\begin{array}{l}\text { Children with CCHS } \\
\text { consulted in past }\end{array}$ & \multicolumn{5}{c}{ Respondents, $\mathbf{n}$} \\
\cline { 2 - 5 } year, $\mathbf{n}$ & $\begin{array}{c}\text { Total } \\
(\mathbf{n}=\mathbf{5 8})\end{array}$ & $\begin{array}{c}\text { Respirology Neonatology } \\
(\mathbf{n}=\mathbf{2 6})\end{array}$ & $\begin{array}{c}\text { Neurology } \\
(\mathbf{n}=\mathbf{2 1})\end{array}$ & \begin{tabular}{c}
$\mathbf{n}=\mathbf{1 1})$ \\
\hline 0
\end{tabular} \\
28 & 6 & 15 & 7 \\
1 & 16 & 8 & 5 & 3 \\
2 & 7 & 5 & 1 & 1 \\
3 & 3 & 3 & 0 & 0 \\
4 & 1 & 1 & 0 & 0 \\
5 & 1 & 1 & 0 & 0 \\
7 & 1 & 1 & 0 & 0 \\
10 & 1 & 1 & 0 & 0 \\
Total & 65 & 53 & 7 & 5 \\
\hline
\end{tabular}

\section{METHODS}

A web-based survey (SurveyMonkey.com, LLC, USA) was sent to 303 pediatric subspecialists in Canada: 85 pediatric respirologists, 77 pediatric neurologists and 141 neonatologists. This represents approximately $85 \%$ of pediatric respirologists, $62 \%$ of pediatric neurologists and $67 \%$ of neonatologists in Canada (personal communications: S Demarais, CTS; D Irvine, Canadian Neurological Association; Dr D Bhatt, Database Committee Chair of the Canada and USA Neonatology Chapters of the American Academy of Pediatrics). These three specialties were chosen because they are often involved in the diagnosis and surveillance of children with CCHS. The e-mail addresses of the pediatric practitioners were obtained from hospital websites and/or telephone communication with administrative personal for the pediatric hospitals and adult hospitals with pediatric beds across the country. Hospital-based physicians were targeted because clinical care would most likely be provided by pediatric hospital-based specialists given the need for specialized care and pediatric polysomnograms. The survey was developed by the authors. It included a total of 36 questions divided into three parts: Responder characteristics (five questions); Disease diagnosis (six questions); and Disease surveillance (25 questions) (Appendix 1). Differences in responses among subspecialties were evaluated for each question, where feasible, using the Kruskal-Wallis test. Given the potential for multiple comparisons among groups, a two-sided $\mathrm{P} \leq 0.01$ was considered to be statistically significant. Participants were informed that a completed survey implied consent to participate in the study. Ethics approval for the present study was received from SickKids Hospital Research Ethics Board (Toronto, Ontario). A firewall exists in the IWK Health Centre (Halifax, Nova Scotia); therefore, at the request of one respondent,
TABLE 4

Autonomic nervous system (ANS) dysfunction symptoms and conditions observed in children with congenital central hypoventilation syndrome (CCHS) reviewed by Canadian pediatric respirologists in the past year $(n=53)$

\begin{tabular}{lc}
\hline $\begin{array}{l}\text { ANS dysfunction symptoml } \\
\text { condition }\end{array}$ & Children with CCHS, $\mathbf{n}(\%)$ \\
\hline Hirschsprung disease & $13(25)$ \\
Arrythmias & $6(11)$ \\
Neural crest tumours & $3(6)$ \\
Pulmonary hypertension & $4(8)$ \\
Pupillary dysfunction & $6(11)$ \\
Polycythemia & $0(0)$ \\
Gastrointestinal dysmotility & $5(9)$ \\
\hline
\end{tabular}

questionnaires were mailed to and returned by one central administrative assistant. The results from each survey were anonymous and confidential. The present study was conducted from February to March 2012.

\section{RESULTS}

Responder characteristics

A total of 83 (27\%) participants responded to the survey. Forty-seven $(57 \%)$ were male. Seventy-seven $(93 \%)$ participants practice in a tertiary centre. The remainder practice in a community setting. Table 1 summarizes the response rates according to the number of surveys sent and geographical region. Table 2 summarizes the response rates according to subspecialty. However, not all of the respondents answered all of the questions. Seven $(8.5 \%)$ respondents have been in medical practice for zero to 10 years, 35 (43\%) respondents for 11 to 20 years, 14 (17\%) respondents for 21 to 30 years, 19 (23\%) respondents for 31 to 40 years and seven $(8.5 \%)$ respondents for 41 to 50 years. One individual did not answer the question. Seven physicians graduated in 2003 or later, the year the PHOX2 gene was discovered.

\section{Disease diagnosis}

Seventy-four pediatric subspecialists responded to this section of the questionnaire. Fifty-eight (78\%) of the 74 respondents had consulted on one or more children with CCHS in their lifetime. Five (7\%) of the pediatricians had previously consulted on $>10$ CCHS children in their lifetime. A pediatric neurologist who had consulted on 20 children had seen the highest number of CCHS children in the study. Sixtyfive children with CCHS have been seen in the past year by a total of 58 respondents (Table 3). Fifty-three of these 65 children were reviewed by respirologists in the past year. The number of children with identified symptoms of autonomic nervous system dysfunction are shown in Table 4.

With regard to the ordering of diagnostic tests for CCHS, 14 (25\%) of the 54 respondents did not order genetic testing, either alone or with another test, to make a diagnosis of CCHS. These respondents included eight neonatologists, five neurologists and one respirologist. The recommended tests to make a diagnosis of CCHS - genetic testing, diagnosis of exclusion (the absence of primary lung, cardiac, or neuromuscular disease or an identifiable brainstem lesion), polysomnogram plus or minus a hypercapnic challenge test - were only all routinely ordered by $23(43 \%)$ of the 54 respondents (Table 5). For children with suspected CCHS, 37 of $52(71 \%)$ respondents order genetic testing for PHOX2B and 48 of 52 (92\%) send families for genetic counselling after a confirmed diagnosis.

\section{Disease surveillance}

The results for the disease surveillance section of the questionnaire are only presented for the pediatric respirology respondents because no neonatologists and only one neurologist currently follow a child with CCHS. The small number of respirology respondents in some regions of the country precluded statistical analysis. 
TABLE 5

Diagnostic tests ordered by pediatric practitioners to make a diagnosis of congenital central hypoventilation syndrome

\begin{tabular}{|c|c|c|c|c|}
\hline \multirow[b]{2}{*}{ Diagnostic test } & \multirow[b]{2}{*}{ All $(n=54)$} & \multicolumn{3}{|c|}{ Respondents, $\mathrm{n}$} \\
\hline & & Respirology $(n=25)$ & Neonatology $(n=19)$ & Neurology $(n=10)$ \\
\hline Genetic testing, PSG and diagnosis of exclusion & 18 & 15 & 2 & 1 \\
\hline Genetic testing not ordered & 14 & 1 & 8 & 5 \\
\hline
\end{tabular}

Only the most frequent combinations of genetic testing plus another test are shown. PSG Polysomnography

Nineteen respirologists who had consulted on a total of 103 children with CCHS had responded to the ventilatory management question for 98 children with the following responses: invasive ventilation $(n=45[46 \%])$; noninvasive ventilation $(n=39$ [40\%]); daytime diaphragmatic pacing and nocturnal invasive ventilation ( $\mathrm{n}=9[9 \%])$; and initial invasive ventilation followed by a switch to noninvasive ventilation $(n=5[5 \%])$. Four respirologists offered diaphragmatic pacing to their patients. Of the 19 respirology respondents, seven (37\%) based the decision for the modality of ventilation on the clinical symptoms, one (5\%) based the decision on the CCHS guidelines and 11 (58\%) based this decision on a combination of both.

Nineteen respirology respondents consulted on a total of 109 children with CCHS, of whom 99 (91\%) received polysomnograms. Seven (41\%) of the 17 respirologists did not change the frequency with which polysomnographies are performed depending on age. Seven $(37 \%)$ of the 19 respondents aimed for a carbon dioxide range of $35 \mathrm{mmHg}$ to $40 \mathrm{mmHg}$ during polysomnogram titrations.

With regard to cardiac evaluation, nine of $20(45 \%)$ respondents order Holter monitors at the time of diagnosis only. Ten $(71 \%)$ of the 14 pediatric practitioners do not change the frequency of ordering Holter monitors based on the age of the child. Three (17\%) of the 18 respondents order echocardiograms at the time of diagnosis, six of 18 (33\%) respondents order them yearly, three of $18(17 \%)$ respondents performed them less frequently than once per year, three of $18(17 \%)$ respondents only performed them depending on the clinical situation, two of $18(17 \%)$ respondents did not know and one $(6 \%)$ respondent never performed them.

Twenty-four per cent $(n=4)$ of respirology respondents never order urine screening for neural crest tumours. Eight (47\%) of the 17 respirologists order an abdominal ultrasound at the time of diagnosis only. Of the 19 respondents, two (11\%) never order a hematocrit and reticulocytes to test for polycythemia associated with chronic hypoxemia. Thirty-five per cent $(n=6)$ of the respirology respondents order neurocognitive testing for their CCHS patients.

With regard to surveillance in the respirology clinic, five of 19 (26\%) respondents see patients with CCHS every three months, nine of 19 (47\%) review CCHS children every six months, one respirologist admits these children every six months, three of 19 (16\%) review these children with variable frequency according to ventilation adherence, age or distance to travel, and one (5\%) respondent did not know. This is performed either yearly or every two years. Sixty-three per cent of respirologists (10 of 16) refer newly diagnosed CCHS children to opthamology, 12 of $18(67 \%)$ recommend 'MedicAlert' bracelets, nine of $19(47 \%)$ counsel about drugs and alcohol and 15 of 19 (79\%) counsel these children about safe swimming practices. Sixty-seven per cent (12 of 18) of respirologists order home oximeters for children with CCHS. Other diagnostic tests for surveillance of CCHS children include chest radiographs, blood pressure monitoring, electrocardiograms, otolaryngology referral, end tidal carbon dioxide measurements, capillary blood gases at clinic visits and overnight oximetry every six months.

\section{DISCUSSION}

Our study is the first to report on the current state of the disease diagnosis and surveillance of CCHS by pediatric practitioners across Canada. Our results demonstrate that there are significant differences in current practice compared with the recommendations outlined in the 2010 ATS Clinical Policy Statement for CCHS. Therefore, an opportunity exists to improve clinical care by building on this work to identify whether these differences are a result of knowledge gaps or resources barriers within the Canadian health care system or a combination of both.

The disease-defining gene for CCHS, $\mathrm{PHOX} 2 \mathrm{~B}$, was discovered almost 10 years ago and has revolutionized the clinical practice of CCHS. Therefore, it is surprising that $25 \%$ of Canadian pediatric specialists, almost all of whom practice in tertiary centres, would not order genetic testing when investigating a patient with suspected CCHS. The first clinical implication of this lack of genetic testing is whether the presumed diagnosis of CCHS is correct. A second clinical implication is that genetic testing of parents and siblings, and genetic counselling would potentially not be offered. Although $90 \%$ of parents of children with CCHS do not carry a PHOX2B mutation, $10 \%$ of CCHS mutations are believed to have been inherited from asymptomatic parents with somatic mosaicism $(1,6,7)$. Somatic mosaicism confers up to a $50 \%$ risk of CCHS in offspring. Using more sophisticated techniques for genetic analyses, Bachetti et al (8) and Maguro et al (9) recently demonstrated that up to $25 \%$ of affected children with CCHS inherited an expanded mutation from a parent with late-onset central hypoventilation syndrome or an asymptomatic parent with somatic mosaicism or constitutive mutation. This underscores the importance of genetic counselling for families of CCHS children.

Genetic testing to identify specific PHOX2B mutations is essential to make a diagnosis of CCHS; also, specific mutations are more commonly associated with different clinical phenotypes, such as severity of the ventilatory defect, as well as the risk of developing some of the other associated symptoms of autonomic nervous system dysfunction. This information is useful for newly diagnosed families trying to understand the effect of this disease on their child's day-to-day life and future, and also helps guide surveillance practices (eg, need for neuroblastoma screening).

Significant practice deviation existed with respect to disease management among respirologists. For example, although $>90 \%$ of respirologists order polysomnograms across the country, only $37 \%$ aim for a carbon dioxide level within the range recommended in the ATS statement. This suggests that many patients may not be receiving management for their hypoventilation based on the current guidelines. In addition, the majority of respirologists do not change the frequency with which neurocognitive, cardiac and oncological screening is performed. As such, children $<3$ years of age who are the most vulnerable subpopulation may not be screened as frequently as recommended. With respect to anticipatory guidance, $<50 \%$ of respirologists are counselling families about the central nervous system depressant effects of alcohol and drugs. This is essential because there are documented reports of sudden death in teenagers with CCHS who have consumed alcohol (10)

Our data indicate that a relatively small number of respirologists, the majority of whom have only one patient with CCHS in their practice, follow the reported Canadian CCHS population of slightly more than 50 children. The ATS Statement regarding CCHS suggests that physicians who have cared for fewer than 15 to 30 patients with CCHS may not have sufficient experience with the disease and, thus, recommends referral to regional centres for management (3). Presently, 
this would mean that there are no pediatricians in Canada that the ATS Task Force would deem to have sufficient expertise to care for these children. Although referral to an American centre is not a practical solution, this raises an important question as to how to best to serve this rare population within the realms of existing Canadian resources. We propose that the first step would be a formal review of the 2010 ATS guidelines, and an educational intervention in conjunction with the identification of barriers to access of resources preventing national implementation. This would then be followed by the development of a Canadian CCHS registry to allow all respirologists in the country to benefit from the collective management of these children. Additionally, the proportion of children that have the central hypoventilation phenotype and are $\mathrm{PHOX} 2 \mathrm{~B}$ positive is not currently known and is an area of needed future study.

There were several limitations to our study. First, the overall survey response rate was lower than other published Canadian surveys of pediatric subspecialists but not dissimilar from other recently published pediatric Internet-based survey results (11-14). The lower response rate may be related to the rarity of the disease. Although the overall survey response rate was only $27 \%$, the geographical distribution of the respondents does represent the demographics of pediatric respirologists, pediatric neurologists and neonatologists across the country, with the exception of the Maritimes. There was over-representation of the neurology and neonatology responses from the Maritimes. However, this is likely to be of minimal significance because the disease surveillance results were based on respirology respondents only. Second, the questionnaire did not ask for the results of genetic testing for the patients with CCHS who are or have been followed by the respondents. Thus, it is not clear whether patients reported to have CCHS actually fulfilled criteria for the diagnosis of CCHS. The authors chose not to ask this question because this information may require additional chart review(s) by responding clinicians and, thus, could detract from completion of the already lengthy survey. Third, the number of CCHS children consulted on by the pediatricians was not an accurate estimate of the pediatric prevalence of CCHS. We chose a convenience sample of tertiary practitioners across Canada believed to be representative of the country; it is possible that some physicians and, therefore, some patients were missed. In addition, as mentioned above, patients reported as having CCHS may not have undergone diagnostic genetic testing, leading to false-positive reporting. Furthermore, multiple respondents may have seen the same patient, making an estimation of the actual number of cases of CCHS very difficult within the realm of our study. We did not survey pediatric oncologists or clinical geneticists, two other subspecialists often involved in the diagnosis and care of patients with $\mathrm{PHOX} 2 \mathrm{~B}$ mutations. However, the primary objective of our study was to understand the diagnostic and surveillance practices across Canada rather than disease prevalence, and the planned disease registry will address prevalence and, potentially, mutational spectrum and associated symptoms. Finally, in the present survey, we evaluated what practitioners were doing but did not specifically ask why. Therefore, it remains unclear as to whether these practice deviations are a result of a knowledge gap versus limited access to resources or both. However, the present analysis provides an initial needs assessment for future study to distinguish between these two and significantly advance care for these children.

\section{CONCLUSIONS}

Our study demonstrated that there are significant deviations in practice from the 2010 ATS Clinical Policy Statement on CCHS. There is a need for both a Canadian educational intervention as well as an identification of barriers faced by clinicians trying to implement these guidelines to improve the quality of care for these children. We need to bridge the existing knowledge gap and overcome barriers to access to resources faced by clinicians to ensure best practice for children with CCHS.

ACKNOWLEDGEMENTS: The authors thank the pediatric respirologists, pediatric neurologists and neonatologists across the country for participating in the survey.
AUTHOR CONTRIBUTIONS: Study concept and development: RA, TJM, MW, SM, MSI. Questionnaire development: RA. Questionnaire review: TJM, MW. Data analysis: RA, AS. Manuscript writing: RA, TJM, MW. Manuscript editing: RA, TJM, MW, SM, MSI

\section{APPENDIX 1: CCHS QUESTIONNAIRE: CANADIAN PREVALENCE AND DISEASE SURVEILLANCE}

\section{Responder characteristics}

1. In which region of the country do you practice? Western Canada (BC and Alberta)

Central Canada (Saskatchewan and Manitoba)

Eastern Canada (Ontario and Quebec)

Maritimes (New Brunswick, Nova Scotia, Newfoundland, PEI)

Northern Canada (Northwest Territories, Yukon Territories and Nunavut)

2. Which of the following best describes your clinical practice?

General Pediatrics

Pediatric Respirology

Pediatric Neurology

Pediatric Neonatology

Other:

3. Which of the following settings best describes your clinical practice?

Community Based Practice

Tertiary Care Center

Other:

4. What was your year of graduation from medical school?

5. What is your gender?

Male Female

\section{Disease diagnosis}

6. How many patients have you consulted on with congenital central hypoventilation syndrome in the past year?

7. How many are alive?

8. How many are dead?

9. How do you make a diagnosis of CCHS? (check all that apply) Genetic testing for PHOX2B

Polysomnogram

Hypercapnic challenge test

Diagnosis of exclusion: rule out CNS structural abnormality, metabolic, neurologic, cardiac, neuromuscular disease, primary lung disease Other:

10a. Do you send DNA for PHOX2B genetics? Yes No

10b. If yes, where do you send the DNA for PHOX2B genetics? Ambry genetics

Dr Debbie Weese-Mayer's lab

Other:

11. Are patients and families routinely offered genetic counseling after diagnosis?

Yes No

\section{Disease surveillance}

12. How often are sleep studies done for patients with CCHS:

Biannually or more

Annually

Every 18 months

Only if clinically indicated

Other:

13. Does the frequency of polysomnograms being performed for CCHS patients change with age?

Yes No

a) If yes, how so? 
14. What is the target $\mathrm{CO}_{2}$ range during polysomnogram titrations? $30-34 \mathrm{mmHg}$

$35-40 \mathrm{mmHg}$

$45-50 \mathrm{mmHg}$

Other:

15. How frequently are Holter monitors done on CCHS patients? (check all that apply)

at time of diagnosis

q 0-6months

q yearly

q 2 yearly

Other:

16. Does the frequency of Holter monitors being performed for CCHS patients change with age?

Yes No

a) If yes, how so?

17. How long the Holter monitors are kept on for at your center for CCHS patients?

24 hours

48 hours

72 hours

Other:

18. How frequently are echocardiograms performed for CCHS patients?

Never

At time of diagnosis

q 3 months

q 6 months

q yearly

Other:

19. Does the frequency of echocardiograms being performed for CCHS patients change with age?

Yes No

a) If yes, how so?

20. How frequently are hematocrits and reticulocytes performed for CCHS patients?

never

at time of diagnosis

q 3 months

q 6 months

q yearly

Other:

21. Does the frequency of hematocrits and reticulocytes being performed for CCHS patients change with age?

Yes No

b) If yes, how so?

22. How frequently are urine VMA and HVA performed for CCHS patients?

never
at time of diagnosis
q $0-3$ months
q 6 months
q12 months
Other:

23. Does the frequency of urine VMA and HVA being performed for CCHS patients change with age?

Yes No

a) If yes, how so?

24. How frequently are abdominal ultrasounds performed for CCHS patients?

Never

At time of diagnosis

q $0-3$ months

q 6 months

q12 months

Other:
25. Does the frequency of urine VMA and HVA being performed for CCHS patients change with age? Yes No

a) If yes, how so?

26. Is neurocognitive testing performed for all patients?

Yes No

a) If yes, how frequently is the testing being performed?

b) If yes, what specific testing is being performed?

27. Is autonomic nervous system testing performed for all patients? Yes No

a) If yes, what specific testing is being performed and how frequently (click all that apply)?

Tilt table testing:

Valsalva:

Pupillometry:

Thermal Stresses:

Other:

28. Are all newly diagnosed patients referred to Ophthalmology? Yes No

a) If not, when would patients be referred?

29. Are patients routinely offered a medical alert bracelet? Yes No

30. Are patients routinely counseled about alcohol and drug use? Yes No

31. Are patients routinely counseled about swimming? Yes No

32. Are stage 1 exercise tests routinely performed for patients with CCHS?

Yes No

a) If yes, how often are they performed?

At time of diagnosis

If clinically indicated

Biannually

Annually

Other:

33. How often are CCHS patients seen in the respiratory medicine clinic?

q $0-3$ months

q 6 months

q12 months

Other:

34. Do all of the CCHS patients have an oxygen saturation monitor at home?

Yes No

a) If not, how many patients do not?

35. Do any of the CCHS patients have a carbon dioxide monitor at home?

Yes No

a) If yes, how many?

36. Are there any other components of disease surveillance that your centre routinely performs for CCHS patients?

Yes No

a) If yes, what tests are performed and what is the frequency? 


\section{REFERENCES}

1. Weese-Mayer DE, Berry-Kravis EM, Zhou L, et al. Idiopathic congenital central hypoventilation syndrome: Analysis of genes pertinent to early autonomic nervous system embryologic development and identification of mutations in $\mathrm{PHOX} 2 b$. Am J Med Genet A 2003;123A:267-78.

2. Amiel J, Laudier B, Attie-Bitach T, et al. Polyalanine expansion and frameshift mutations of the paired-like homeobox gene PHOX2B in congenital central hypoventilation syndrome. Nat Genet 2003;33:459-61.

3. Weese-Mayer DE, Berry-Kravis EM, Ceccherini I, Keens TG, Loghmanee DA, Trang H. An official ATS clinical policy statement: Congenital central hypoventilation syndrome: genetic basis, diagnosis, and management. Am J Respir Crit Care Med 2010;181:626-44.

4. Idiopathic congenital central hypoventilation syndrome. Am J Respir Crit Care Med 1999;160:368-73.

5. McKim DA, Road J, Avendano M, et al. Home mechanical ventilation: A Canadian Thoracic Society clinical practice guideline. Can Respir J 2011;18:197-215.

6. Trochet D, Hong SJ, Lim JK, et al. Molecular consequences of PHOX2B missense, frameshift and alanine expansion mutations leading to autonomic dysfunction. Hum Mol Genet 2005;14:3697-708.

7. Berry-Kravis EM, Zhou L, Rand CM, Weese-Mayer DE. Congenital central hypoventilation syndrome: PHOX2B mutations and phenotype. Am J Respir Crit Care Med 2006;174:1139-44.
8. Bachetti T, Parodi S, Di Duca M, Santamaria G, Ravazzolo R, Ceccherini I. Low amounts of PHOX2B expanded alleles in asymptomatic parents suggest unsuspected recurrence risk in congenital central hypoventilation syndrome. J Mol Med (Berl) 2011;89:505-13.

9. Meguro T, Yoshida Y, Hayashi M, et al. Inheritance of polyalanine expansion mutation of $\mathrm{PHOX} 2 \mathrm{~B}$ in congenital central hypoventilation syndrome. J Hum Genet 2012;57:335-7.

10. Chen ML, Turkel SB, Jacobson JR, Keens TG. Alcohol use in congenital central hypoventilation syndrome. Pediatr Pulmonol 2006;41:283-5

11. Katz SL, McKim D, Hoey L, et al. Respiratory management strategies for Duchenne muscular dystrophy: Practice variation amongst Canadian sub-specialists. Pediatr Pulmonol 2013;48:59-66.

12. Taddio A, Pulleyblank R, Stephens D, McNair C, Shah V. Canadian neonatologist practices regarding opioid use in ventilated and spontaneously breathing infants undergoing medical procedures. Clin J Pain 2010;26:422-8.

13. Dooley JM, Camfield PR, Camfield CS, Gordon KE, Fraser AD. The use of antiepileptic drug levels in children: A survey of Canadian pediatric neurologists. Can J Neurol Sci 1993;20:217-21.

14. Keane VA, Hudson AR, King JC Jr. Pediatrician attitudes concerning school-located vaccination clinics for seasonal influenza. Pediatrics 2012;129(Suppl 2):S96-S100. 


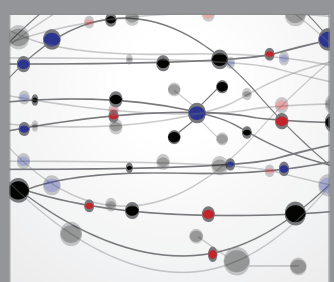

The Scientific World Journal
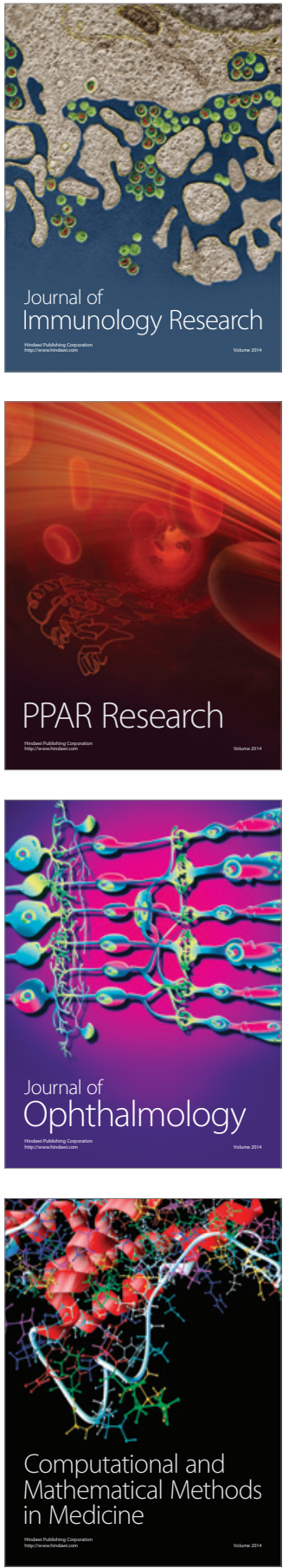

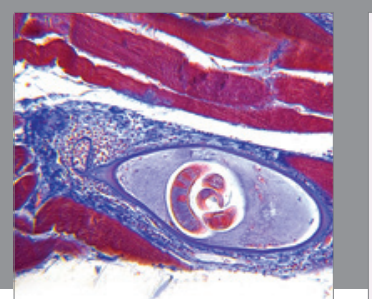

Gastroenterology Research and Practice

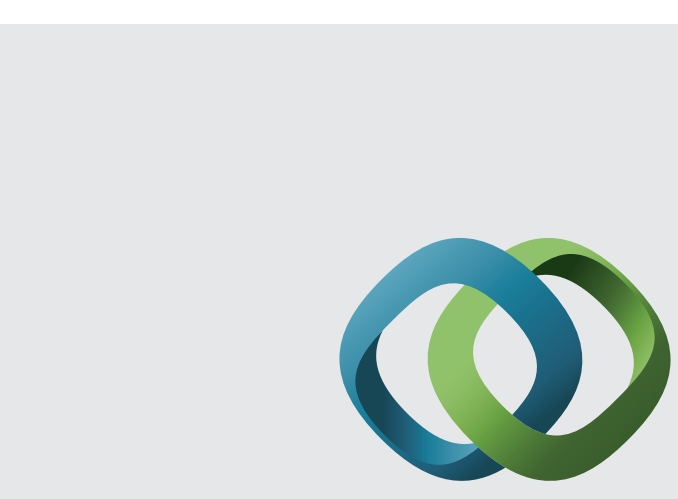

\section{Hindawi}

Submit your manuscripts at

http://www.hindawi.com
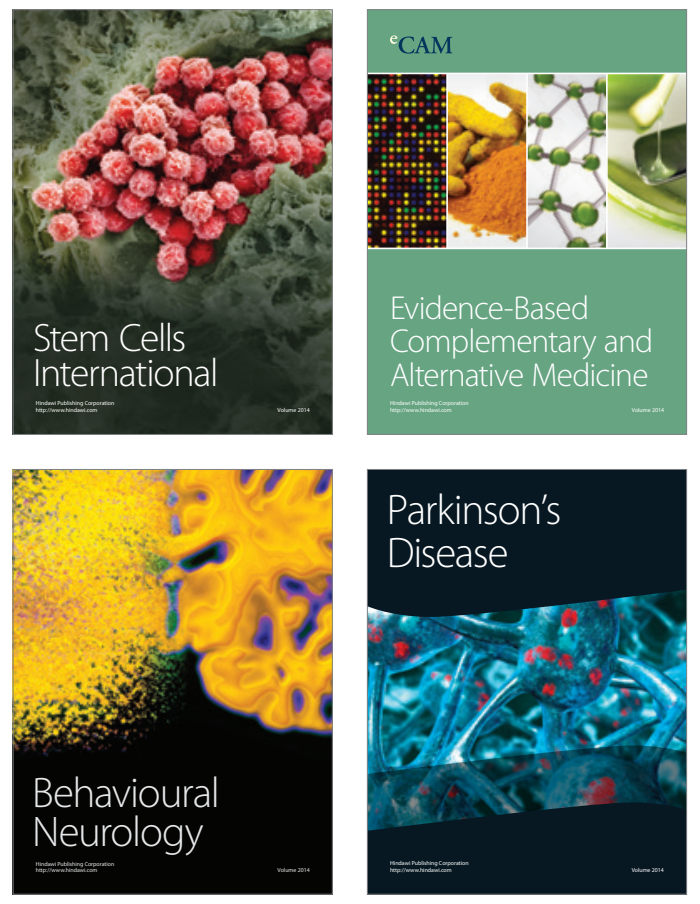
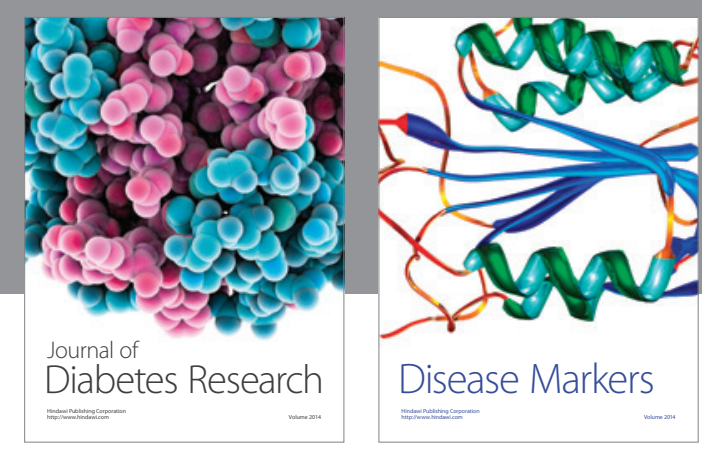

Disease Markers
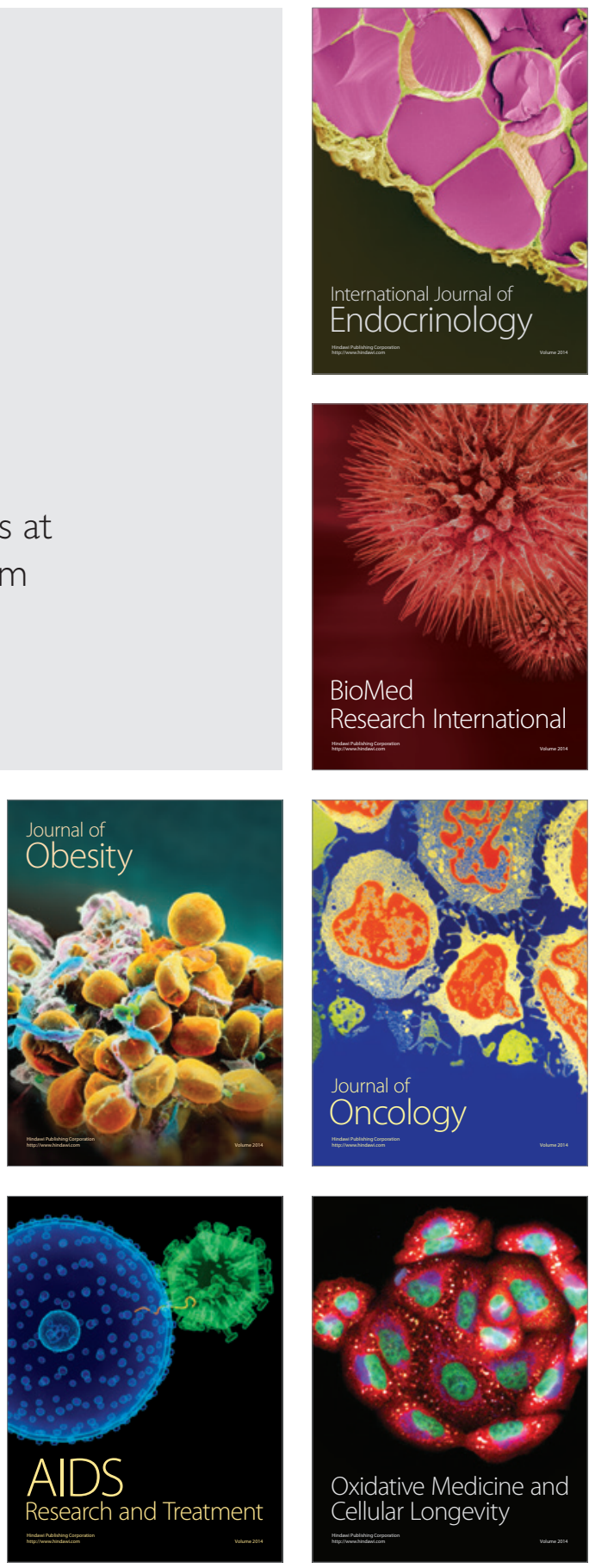